\title{
Article \\ The Focusing Waves Induced by Bragg Resonance with V-Shaped Undulating Bottom
}

\author{
Haiming Zhang ${ }^{1,2}$, Aifeng Tao ${ }^{1,2, *}$, Junhao Tu ${ }^{1,2}$, Junwei Su ${ }^{1,2}$ and Shuya Xie ${ }^{1,2}$ \\ 1 Key Laboratory of Ministry of Education for Coastal Disaster and Protection, Hohai University, \\ Nanjing 210024, China; haiming@hhu.edu.cn (H.Z.); tu54@hhu.edu.cn (J.T.); 171303020052@hhu.edu.cn (J.S.); \\ Xieshuya@hhu.edu.cn (S.X.) \\ 2 College of Harbour, Coastal and Offshore Engineering, Hohai University, Nanjing 210024, China \\ * Correspondence: aftao@hhu.edu.cn; Tel.: +86-15295540618
}

check for updates

Citation: Zhang, H.; Tao, A.; Tu, J.; $\mathrm{Su}, \mathrm{J} . ; \mathrm{Xie}, \mathrm{S}$. The Focusing Waves Induced by Bragg Resonance with V-Shaped Undulating Bottom. J. Mar. Sci. Eng. 2021, 9, 708. https:// doi.org/10.3390/jmse9070708

Academic Editors: Shih-Chun Hsiao, Wen-Son Chiang and Wei-Bo Chen

Received: 19 May 2021

Accepted: 24 June 2021

Published: 27 June 2021

Publisher's Note: MDPI stays neutral with regard to jurisdictional claims in published maps and institutional affiliations.

Copyright: (c) 2021 by the authors. Licensee MDPI, Basel, Switzerland. This article is an open access article distributed under the terms and conditions of the Creative Commons Attribution (CC BY) license (https:// creativecommons.org/licenses/by/ $4.0 /)$.

\begin{abstract}
Intensive wave reflection occurs when the wavelengths of the incident waves and bottom undulations are in a 2:1 ratio. Existing studies have included the Bragg resonance phenomenon of waves passing over a continuous undulating bottom parallel to and oblique to the shoreline. More generally, the Bragg resonance mechanism is used as a means of coastal protection, rather than wave power generation. To focus the wave energy in a specific area, here, we propose sinusoidal sandbars of a horizontal V-shaped pattern, which is formed by two continuous undulating bottoms inclined at an angle to each other and the center axis of the angle is perpendicular to the shoreline. Based on the high-order spectral (HOS) numerical model, both the characteristics of Bragg resonance induced by the regular waves and random waves are investigated. In the scenario of regular waves, it shows that the wave-focusing effect is related to the angle of the V-shaped undulating bottom, and the optimal angle of inclination for the V-shaped undulating bottom is $162.24^{\circ}$. On that basis, considering the interactions between the random waves and the V-shaped undulating bottom of $162.24^{\circ}$, the Bragg resonance characteristics of random waves are studied. The BFI factor combining wave steepness and spectrum width can evaluate the focusing intensity of the Bragg resonance of the random waves. For $B F I$, in the range of $0.15-1.0$, the values of $H_{\mathrm{smax}} / H_{\mathrm{s} 0}$ linearly increase with the increase of BFI.
\end{abstract}

Keywords: three-dimensional Bragg resonance; regular waves; random waves; high-order spectral (HOS) method; Gaussian spectrum; V-shaped undulating bottom

\section{Introduction}

Ocean waves contain large untapped renewable energy sources, which could be used to fulfil the energy demand [1]. Wave energy has the characteristics of high power density and wide distribution, and is renewable [2]. Hitherto, about one thousand wave energy converter (WEC) inventions have been patented [3], and more than 200 of them have entered the model testing stage [2]. However, present research mainly focuses on promoting the conversion efficiency of wave energy converters by improved mechanical design [4]. There are few research results to improve the wave energy generation efficiency from the perspective of increasing the wave energy density of the target sea area. Taking the characteristics of Bragg resonance into account is a good idea for wave energy focusing.

Bragg reflection or resonance is initially referred to as a special physical optical phenomenon of X-rays [5]. In the 1980s, Davies [6] first studied that Bragg resonance occurs if the bottom wavelength is an integral multiple of half wavelength of the incident waves. A followed idea originated for coastal protection was put forward. The strong reflection of water waves by seabed bars was investigated experimentally $[7,8]$ as well as theoretically [9-11]. Afterwards, Bailard et al. [12] have extensively studied theoretically, computationally and experimentally to learn explicitly the feasibility of using longshore seabed bars to protect the shore and summarized its effectiveness and limitations. Some issues, including the partially standing-wave pattern [13] and shoreward increase 
of wave amplitude [14-16] by Bragg reflection, were exposed. Howard \& Yu [17] and Weidman et al. [18] have demonstrated that a specific phase relationship of wave-bottom interactions is significant, and sometimes it can cause exponentially varying standing-wave patterns. It is illustrated that Bragg resonance leads to offward intense reflection, even shoreward wave amplitude increase. Considering the strong effect of Bragg resonance, more studies focus on coastal protection or beach erosion from the aspect of the backward of the seabed bars.

Subsequent investigations of Bragg resonance mechanism in the field of coastal protection and engineering application pay more attention to the actual situations, e.g., oblique incident waves [10,19-22], sub- and superharmonic frequency [19-23], and seabed configuration $[10,21,22,24]$.

Recently, Couston et al. [22] have proposed to revamp the Bragg resonance mechanism as a means of coastal protection by considering oblique seabed bars that divert, rather than reflect, shore-normal incident waves to the shore-parallel direction. Indeed, the novelty that with two superposed sets of oblique seabed bars reflecting waves along the shore-parallel direction, becomes efficiently deflected far to the sides, leaving a wake of decreased wave activity downstream of the patch. However, the wave characteristics of the forward of the oblique seabed bars are not studied by Couston et al. By contrast, few studies concern the wave reflection of the forward. From another perspective of the seabed bars reflecting waves, the wave-bottom interactions due to Bragg resonance may be of interest and be more in accordance with wave power generation need.

In the cases where closed-form solutions cannot be obtained, a wide range of numerical models are available to study water-wave scattering by seabed topographies [22]. These include the extended versions, e.g., the mild-slope equations [11,25], the coupledmode approach [26,27], the integral matching/discretized bottom method [28,29], the fully nonlinear Boussinesq equation adjusted for rapid bottom undulations [30], an asymptotic linear analytical solution (ALAS) [24], and the high-order spectral method [31]. Numerical investigations of Bragg scattering have helped explain several discrepancies between theory and experiments, including the difference between the observed and predicted Class II Bragg resonance frequency due to evanescent modes [32] and the resonant frequency downshift/upshift for the subharmonic/superharmonic Class III Bragg condition due to high-order nonlinearity [30].

Simultaneously, Bragg resonance theory has made some achievements in application fields. A series of submerged breakwaters have been developed to achieve coastal protection based on the Bragg resonance characteristic of reflecting waves to the sea in recent years. For the two-dimensional numerical cases, the parameters' influence on the Bragg resonance reflection coefficient has been investigated by scholars from different aspects, e.g., the shape, height, width, the number of the submerged breakwaters, the slope of the seabed, and wave conditions [33-37]. Generally speaking, these numerical simulations are based on various theoretical methods to study normally incident waves over a series of rectangular or trapezoidal breakwaters. Ning et al. [38] investigated numerically and experimentally the effect of the breakwater shape on hydrodynamic behavior in a two-dimensional flume. Shih \& Weng [39] studied the interactions between waves and various combinations of undulating breakwaters in a three-dimensional basin. The reflection coefficient, transmission coefficient, and attenuation of wave energy were analyzed. Liu et al. [40] examined the Bragg reflection of waves by multiple submerged semi-circular breakwaters, by considering obliquely and normally incident waves independently. Although two-dimensional flume or three-dimensional basin experimental studies have been carried out, the study based on Bragg resonance for improving wave energy generation has not been widely considered. At present, research on the use of wave energy is gradually carried out. Water flow and wave propagation can be altered by artificial terrains or control devices. Zheng et al. [41] carried out a laboratory study on wave-induced setup and wave-driven current in a 2DH reef-lagoon-channel system. Elandt et al. [42] found that gravity waves can focus at a specific location by a concave mirror or a convex 
lens of gravity waves. Tao et al. [43] investigated experimentally strong wave reflection induced by Bragg resonance. They found that wave reflection is effective to amplify the free-surface oscillation amplitude and focus the wave energy in front of the undulating bottom. Zhang \& Ning [44] confirmed that reflected waves from the parabolic opening of the breakwater can travel towards a fixed focus position. For a specified wave environment, the wave heights at the focus positions can reach over several times of the incident wave heights, indicating wave energy multiplication. They all proposed the concept of the focal point. Instead of putting a multitude of wave energy harvesting devices over a large area, a large wave energy absorber can be placed at the focal point. However, the influence of peculiar spatial bottom layouts is ignored, which also affect the focal point and focusing area. Previous physical experiment research [43] shows that waves are strongly reflected in front of the undulating bottom. Based on that, this study considers the wave-focusing effect in a specific area by optimizing the undulating bottom pattern.

The objective of this study is to investigate both the characteristics of Bragg resonance induced by the regular waves and random waves. Three main research questions need to be answered: (1) How does the angle of inclination for the V-shaped undulating bottom affect the wave-focusing characteristics induced by the regular waves? (2) What analytical methods are used to determine the optimal angle of the V-shaped undulating bottom? (3) How do the steepness and spectrum width of random waves affect the wave-focusing characteristics with the V-shaped undulating bottom, and what is the law of their influence on wave height? By the high-order spectral (HOS) numerical simulation, these questions have been examined. The concept of $\mathrm{V}$-shaped undulating bottom is first proposed, i.e., a horizontal V-shaped pattern with two continuous undulating bottoms inclined at the same angle perpendicular to the shoreline. The V-shaped undulating bottom can not only play the role of reflecting waves in front of the undulations, but also exploit the advantage of symmetrical "V-shaped", which can focus waves on the central axis and increase the wave heights in the focusing areas. However, waves in the ocean are stochastic, and the random waves contain wave components of different frequencies, each of which has different Bragg resonance effect due to interactions with the undulating bottom of fixed frequency. Most of the previous studies on wave Bragg resonance only consider the regular waves at the dominant resonance frequency. In addition, there are few studies on Bragg resonance involving the interactions between random waves and undulating bottom. In this work, we have further studied the Bragg resonance characteristics of the interactions between random waves and V-shaped undulating bottom by the numerical simulation of HOS. This study has been organized as follows. In Section 2, the generalized Bragg conditions, the high-order spectral (HOS) method, and the model establishment are introduced. In Section 3, Bragg resonance reflection coefficients of regular waves are studied from the perspectives of different angles $\theta$ and different values $f$. In Section 4, the Bragg resonance focusing characteristics of regular waves and random waves for V-shaped undulating bottom are expounded. In Section 5, the conclusions are provided.

\section{Methods}

According to the high-order spectral (HOS) method [20], an effective computational method for general nonlinear wave-bottom (resonant) interactions and the boundary-value problem are stated.

\subsection{Generalized Bragg Conditions}

The mechanism for Bragg resonances is analogous to that for nonlinear (surface) wave-wave resonant interactions in the absence of bottom undulations. Thus, general Bragg conditions can be deduced from the well-known resonance condition for nonlinear wave-wave interactions [45]. For a wave field over uniform depth $h$, interactions among different wave components become resonant at order $m$ (in wave steepness) if the wave numbers $k_{j}$ and the corresponding frequencies $\omega_{j}$ satisfy: 


$$
\left.\begin{array}{c}
k_{1} \pm k_{2} \pm \cdots \pm k_{m+1}=0 \\
\omega_{1} \pm \omega_{2} \pm \cdots \pm \omega_{m+1}=0
\end{array}\right\}(m \geq 2)
$$

where the same combination of signs is to be taken in both equations, and $k_{j}$ and $\omega_{j}$ satisfy the linear dispersion relation:

$$
\omega_{j}^{2}=g\left|k_{j}\right| \tanh \left|k_{j}\right| h
$$

Generalized Bragg resonance conditions in the presence of bottom ripples are obtained by replacing one or more of the free-surface wave components in Equation (1) by periodic bottom ripple components of corresponding wavenumbers $k_{\mathrm{bj}}$ but with zero frequencies (since the ripples are fixed) [20]. Thus, by combining wavenumbers and frequencies of surface waves and bottom ripples, we obtain general conditions for Bragg resonances at each order, $m=2,3 \ldots$

Here, the Bragg resonance between free wave surface and V-shaped undulating bottom originated satisfies generalized Bragg conditions. In addition, we propose that the first case considers two surface wave components of an incident wavenumber $k_{1}$ and a reflected wavenumber $k_{2}$, propagating over a V-shaped undulating horizontal bottom containing a single wavenumber $k_{\mathrm{b}}$ (analogously to surface waves, which refers to a fixed sinusoidally varying bottom with crest lines normal to $k_{\mathrm{b}}$ ). The first case belongs to Class I Bragg resonance. The second case considers random surface wave generated by the Gaussian spectrum, propagating over a V-shaped undulating horizontal bottom containing a single wavenumber $k_{\mathrm{b}}$ (analogously to surface waves, which refers to a fixed sinusoidally varying bottom with crest lines normal to $k_{\mathrm{b}}$ ). In the paper, Class I Bragg resonance is considered, and numerical simulations all adopt the high-order spectral (HOS) method.

\subsection{High-Order Spectral (HOS) Method}

Combined with the advantages of Zakharov equations and mode-coupling ideas based on potential theory (with the application of the Fast Fourier Transform), the HOS method has been proved as a suitable, robust, and highly efficient numerical method for direct phase-resolved simulation of nonlinear ocean wave field evolution [46-48], wave nonlinear mechanism analysis [49-52] and nonlinear wave-wave interactions and wavebody interactions $[31,53,54]$. In this paper, the HOS numerical model for three-dimensional Bragg resonance is considered based on the HOS method for general nonlinear wavebottom interactions developed by Liu [20]. In addition, the focusing properties of the three-dimensional wave field caused by Bragg resonance with waves passing through V-shaped undulating bottom are studied.

The difficulty of establishing a numerical model is to deal with free-surface boundary conditions. To simplify the calculation, the high-order spectral (HOS) method introduces the velocity potential of the free surface in reference to Zakharov theory [55], so the freesurface boundary condition can be written in the following form:

$$
\left.\begin{array}{l}
\eta_{t}+\nabla_{x} \eta \cdot \nabla_{x} \phi^{s}-\left(1+\nabla_{x} \eta \cdot \nabla_{x} \eta\right) \phi_{z}(x, \eta, t)=0 \\
\phi_{t}{ }^{s}+g \eta+\frac{1}{2} \nabla_{x} \phi^{s} \cdot \nabla_{x} \phi^{s}-\frac{1}{2}\left(1+\nabla_{x} \eta \cdot \nabla_{x} \eta\right) \phi_{z}{ }^{2}(x, \eta, t)=0
\end{array}\right\}
$$

\subsection{Model Establishment}

The V-shaped undulating bottom is shown in Figure 1. It shows that the two continuous undulating bottoms of a horizontal V-shaped pattern, a set of oblique undulations $k_{\mathrm{b} 1}$ (the upper part of the V-shaped pattern). To match with $k_{\mathrm{b} 1}$, the other set of oblique undulations $k_{\mathrm{b} 2}$ (the lower part of the V-shaped pattern matched) is given. The values of $k_{\mathrm{b} 1}$ and $k_{\mathrm{b} 2}$ are the same for a given V-shaped undulating bottom, while the difference of the $k_{\mathrm{b} 1}$ and $k_{\mathrm{b} 2}$ is in the directions of the two vectors. The vectors of $k_{\mathrm{b} 1}$ and $k_{\mathrm{b} 2}$ are symmetric about the $x$-axis. The color vectors in Figure 1 describe simply the V-shaped undulating bottom configuration, where the number of the continuous sinusoidal undulations $N_{\mathrm{b}}=10$, an incident wave wavenumber $k_{1}$ (the direction of $k_{1}$ along the $x$-axis); two bottom undulations wavenumber $k_{\mathrm{b} 1}$ and $k_{\mathrm{b} 2}$ are perpendicular to crest lines of the each 
side of V-shaped undulating bottom respectively; the reflected waves $k_{\mathrm{r} 1}$ and $k_{\mathrm{r} 2}$ due to the two parts of bottom superpose each other ahead of the bottom. In addition, the relationship of the angle $\theta$ between $k_{\mathrm{b} 1} / k_{\mathrm{b} 2}$ and $x$-axis and the angle $\alpha$ between the two sets of oblique crest lines satisfy:

$$
\alpha=180^{\circ}-2 \theta
$$
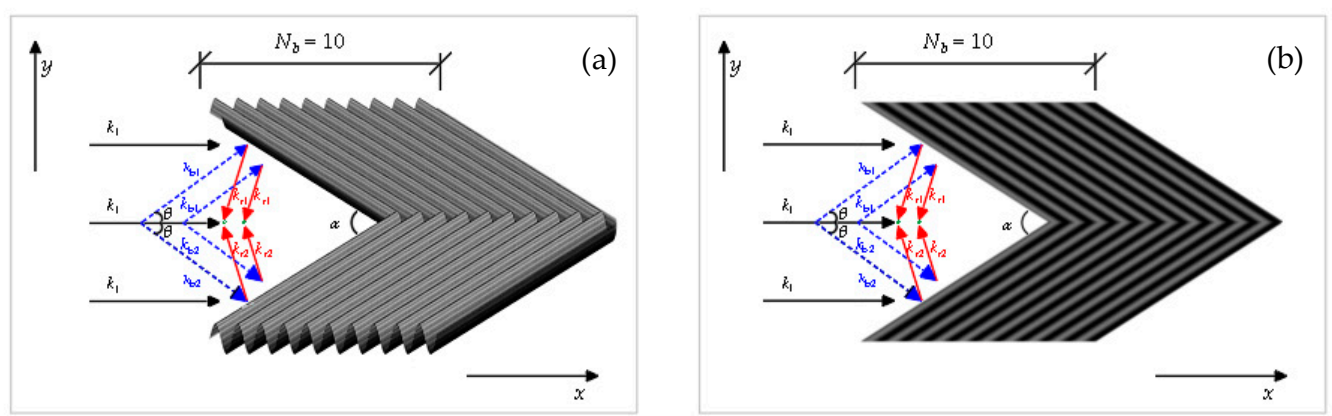

Figure 1. Schematic diagram of the relationship of the angle $\theta$ between $k_{\mathrm{b} 1} / k_{\mathrm{b} 2}$ and $x$-axis and the angle $\alpha$ between the two sets of oblique crest lines: (a) Spatial graph of V-shaped undulating bottom $\left(\alpha<180^{\circ}\right)$; (b) Plane graph of V-shaped undulating bottom $\left(\alpha<180^{\circ}\right)$.

The following parameters for the HOS numerical model are given referring to reference [20]: the undulating bottom $k_{\mathrm{b}} d=0.31$, where $d$ and $k_{\mathrm{b}}$ ( $k_{\mathrm{b}}$ refers to $k_{\mathrm{b} 1}$ and $k_{\mathrm{b} 2}$, and below is the same) are the amplitude and wavenumber of bottom undulations; the incident waves $k_{1} A=0.05$, where $2 A \equiv \eta_{\max }-\eta_{\min }$, where $A, k_{1}, \eta_{\max }$ and $\eta_{\min }$ are the amplitude, wavenumber, maximum elevation, and minimum elevation for surface wave of the incident regular waves respectively; relative water depth $d / h=0.16$, where $d$ and $h$ are the amplitude of bottom and water depth; the total numbers of bottom undulations $N_{\mathrm{b}}=L_{0} / \lambda_{\mathrm{b}}=10$, where $N_{\mathrm{b}}, L_{0}$, and $\lambda_{\mathrm{b}}$ are the number, total length, and wavelength of the sinusoidal undulating bottom respectively; the time step for the fourth-order Runge-Kutta integration $\Delta t$; the total simulation time $T_{\mathrm{s}}$; running steps per period $T / \Delta t=64$, where $T$ is the period of the incident waves; the duration of the simulation periods $T_{\mathrm{S}} / T=20$; node numbers $N_{x} \times N_{y}=512 \times 512$; nonlinear order $M=3$; V-shaped undulating bottom angle $\alpha=90^{\circ}-180^{\circ}$, where 24 values between $90^{\circ}$ and $180^{\circ}$ are distributed unevenly to the angle $\alpha$ of inclination for the $\mathrm{V}$-shaped undulating bottom, as shown in Table 1.

Table 1. The simulation cases of V-shaped undulating bottom angles $\alpha$.

\begin{tabular}{lcccccccccccc}
\hline No. & 1 & 2 & 3 & 4 & 5 & 6 & 7 & 8 & 9 & 10 & 11 & 12 \\
$\alpha\left({ }^{\circ}\right)$ & 180.00 & 178.21 & 176.42 & 174.63 & 172.85 & 168.40 & 167.52 & 165.75 & 162.24 & 160.50 & 155.32 & 151.93 \\
No. & 13 & 14 & 15 & 16 & 17 & 18 & 19 & 20 & 21 & 22 & 23 & 24 \\
$\alpha\left({ }^{\circ}\right)$ & 148.58 & 145.29 & 140.47 & 137.33 & 132.74 & 126.87 & 119.93 & 115.99 & 112.21 & 106.26 & 98.65 & 90.00 \\
\hline
\end{tabular}

\section{Results}

In this study, the three-dimensional Bragg resonance numerical model is validated from two aspects: the first one is to verify the regular wave reflection coefficients under different incident angles $\theta$; the other one is to verify the regular wave reflection coefficients under different wavenumber ratios $f$ ( $f$ is the ratio of 2 times the incident wavenumber $\left(2 k_{1}\right)$ to the undulating bottom wavenumber $\left(k_{\mathrm{b}}\right)$, i.e., $\left.f=2 k_{1} / k_{\mathrm{b}}\right)$. This will prove the accuracy of the model in studying the focusing characteristics of Bragg resonance on V-shaped undulating bottom under different incident angles and different resonance wave numbers.

\subsection{Bragg Resonance Reflection Coefficients of Regular Waves under Different Angles $\theta$}

The Bragg resonance reflection coefficient is the most important parameter to measure the magnitude of Bragg resonance. The Bragg resonance reflection coefficient is calculated according to the method proposed by Liu and Yue [20]. The Bragg reflection resonance coefficients $R(\theta)$ of the Class I Bragg resonance at different incident angles $\theta$ are simulated 
by the three-dimensional HOS method, as shown in Table 2, which are compared with the perturbation theory solutions of Mei [19] (oblique incidence on a finite strip of bars) in Figure 2.

Table 2. Reflection coefficients $R(\theta)$ of Class I Bragg resonance at different incident angles $\theta$.

\begin{tabular}{ccccccccc}
\hline$\theta /\left(^{\circ}\right)$ & 0 & 7.13 & 14.04 & 26.57 & 36.87 & 45.00 & 48.37 & 51.34 \\
$R(\theta)$ & 0.72 & 0.70 & 0.68 & 0.54 & 0.29 & 0 & 0.09 & 0.25 \\
\hline
\end{tabular}

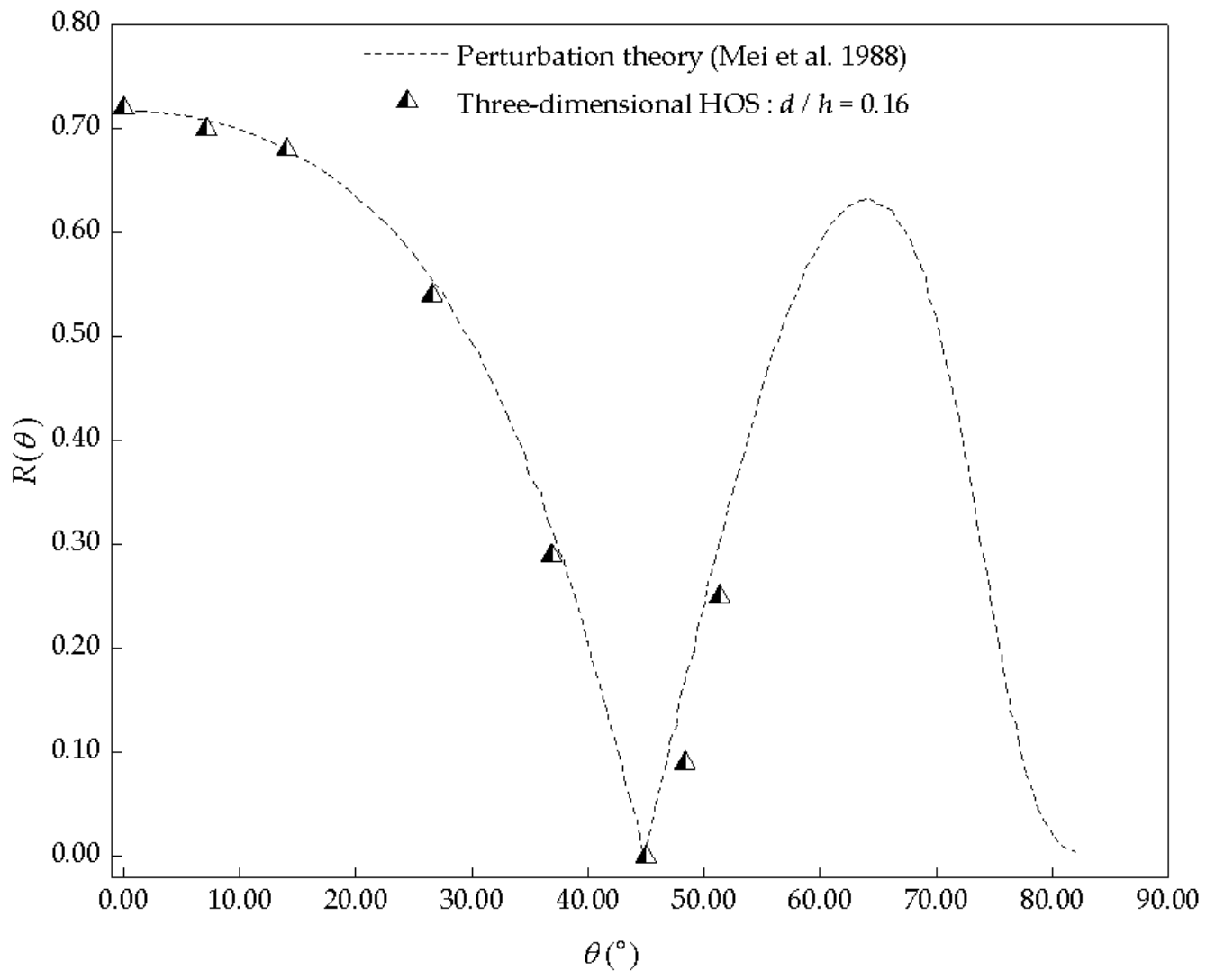

Figure 2. Reflection coefficients $R(\theta)$ comparisons of Class I Bragg resonance.

Figure 2 shows that the three-dimensional HOS method results are in good agreement with the perturbation theory solutions of Mei. When $\theta=0^{\circ}$ (normal incidence), $R(\theta)$ is the largest and up to 0.72 . As $\theta$ increases, $R(\theta)$ first decreases with an increasing decaying rate. When $\theta$ reaches $45^{\circ}, R(\theta)$ decreases to 0 , which means the wave propagation is not affected by the periodic undulating bottom. When $\theta>45^{\circ}, R(\theta)$ exhibits a second maximum point around $\theta=64.5^{\circ}$.

\subsection{Bragg Resonance Reflection Coefficients of Regular Waves under Different Values $f$}

The wavenumber ratios $f$ is determined as 0.9-1.1 due to the study of Liu and Yue [20]. For $f$, in the range of $0.9-1.1,17$ different wavenumber ratios $f$ are uniformly selected to investigate the regular wave reflection coefficients with different values of $f$ under the forward $\left(\theta=0^{\circ}\right)$ and oblique $\left(\theta=19.5^{\circ}\right)$ incident conditions. The results of the threedimensional HOS model and perturbation theory [19] are compared.

According to Figure 3, when $f=0.9-1.1$, the Bragg resonance reflection coefficients increase first and then decrease with the increase of $f$. When $f$ is slightly less than 1.0, the Bragg resonance reflection coefficients reach the peak, which also accords with the phenomenon of Bragg resonance frequency descending. The verification results confirm the reliability of the three-dimensional HOS numerical model. 

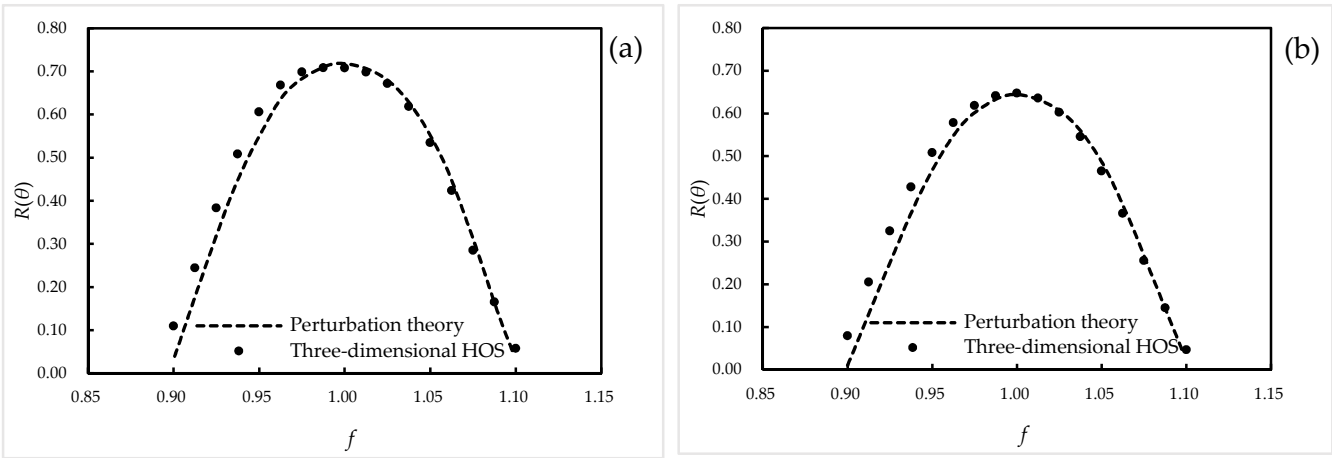

Figure 3. Bragg resonance reflection coefficients of regular waves under different wavenumber ratios $f$ : (a) Forward incident condition $\left(\theta=0^{\circ}\right)$; (b) Oblique incident condition $\left(\theta=19.5^{\circ}\right)$.

\section{Discussion}

4.1. Bragg Resonance Focusing Characteristics of Regular Waves for V-Shaped Undulating Bottom

In the section, the wavelength of the incident wave is $1 \mathrm{~m}$, which need 16 nodes to represent. The other parameters of the incident waves and undulating bottom can be calculated according to the section of the Model Establishment.

\subsubsection{Spatial Distributions of Wave Amplitudes in the Focusing Areas for Regular Waves}

The V-shaped layout can be regarded as the combination of two parts of oblique bottom undulations relative to the incident waves. The wave-focusing effects, therefore, are the effects of two parts of oblique bottom undulations relative to the incident waves. When the wave incident angle (between $k_{1}$ and $k_{\mathrm{b}}$ ) $\theta$ is greater than $45^{\circ}, R(\theta)$ has a secondary maximum. There is a relationship between $\alpha$ and $\theta$, as shown in Figure 1 .

As $\theta$ increases, the $\alpha$ of the V-shaped layout becomes smaller. As a result, the wavefocusing area becomes smaller, so the wave-focusing effect is weakened. The values of $\alpha$ parameter for the specific simulation cases are listed in Table 1.

Bragg resonance occurs when regular waves pass over the V-shaped undulating bottom and satisfy the conditions that the wavelengths of the incident waves and bottom undulations are in a 2:1 ratio. Incident waves and reflected waves from two directions superimposed in front of the bottom causes wave energy focusing effect. Under the condition of regular wave incidence with the same wave amplitude, the Bragg resonance effects of wave-bottom interactions at different V-shaped undulating bottom angles $\alpha$ are simulated by the three-dimensional HOS numerical model. The maximum wave amplitudes calculated $\left(A_{\max }\right)$ are compared with the incident wave amplitude $\left(A_{0}\right)$, and the spatial distribution characteristics of wave amplitudes are analyzed by $A_{\max } / A_{0}$. The maximum wave amplitudes calculated $\left(A_{\max }\right)$ are different at different node positions. So, the values of $A_{\max } / A_{0}$ is also different. Table 3 shows that the calculated wave amplitude increases change at the focal points corresponding to different $\alpha\left(90^{\circ} \leq \alpha \leq 180^{\circ}\right)$. The node position of the maximum value of $A_{\max } / A_{0}$ for each simulation case is called the focal point, and then $A_{\operatorname{maxp}} / A_{0}$ is used to denote the value of $A_{\max } / A_{0}$ at the focal point. When $\alpha=180^{\circ}$ (the incident wave direction $k_{1}$ is parallel to the bottom $k_{\mathrm{b}}$ ), the calculated wave amplitude at the focal point increases to 1.81 times the initial incident wave amplitude. As $\theta$ increases, the $\alpha$ of the V-shaped layout becomes smaller. As a result, the wave-focusing area becomes smaller, so the wave-focusing effect is weakened. In conclusion, $90^{\circ} \leq \alpha \leq 180^{\circ}$ is mainly considered in this study. 
Table 3. The calculated wave amplitude increases at the focal points corresponding to different angles $\alpha$.

\begin{tabular}{ccccccccc}
\hline$\alpha\left({ }^{\circ}\right)$ & 180.00 & 178.21 & 176.42 & 174.63 & 172.85 & 168.40 & 167.52 & 165.75 \\
$A_{\operatorname{maxp}} / A_{0}$ & 1.81 & 1.91 & 2.08 & 2.22 & 2.33 & 2.79 & 2.83 & 2.86 \\
$\alpha\left({ }^{\circ}\right)$ & 162.24 & 160.50 & 155.32 & 151.93 & 148.58 & 145.29 & 140.47 & 137.33 \\
$A_{\operatorname{maxp}} / A_{0}$ & 2.87 & 2.78 & 2.44 & 2.21 & 1.92 & 1.73 & 1.56 & 1.47 \\
$\alpha\left({ }^{\circ}\right)$ & 132.74 & 126.87 & 119.93 & 115.99 & 112.21 & 106.26 & 98.65 & 90.00 \\
$A_{\operatorname{maxp}} / A_{0}$ & 1.46 & 1.37 & 1.30 & 1.22 & 1.20 & 1.16 & 1.14 & 1.11 \\
\hline
\end{tabular}

To better analyze the spatial distribution characteristics of wave amplitudes, $\alpha=178.21^{\circ}$, $168.40^{\circ}, 162.24^{\circ}, 155.32^{\circ}, 148.58^{\circ}$, and $140.47^{\circ}$ are selected for comparison. The spatial distributions of wave amplitudes in the focusing areas due to Bragg resonance at different V-shaped undulating bottom angles $\alpha$ are analyzed, the values of $A_{\max } / A_{0}$ are shown in Figure 4.
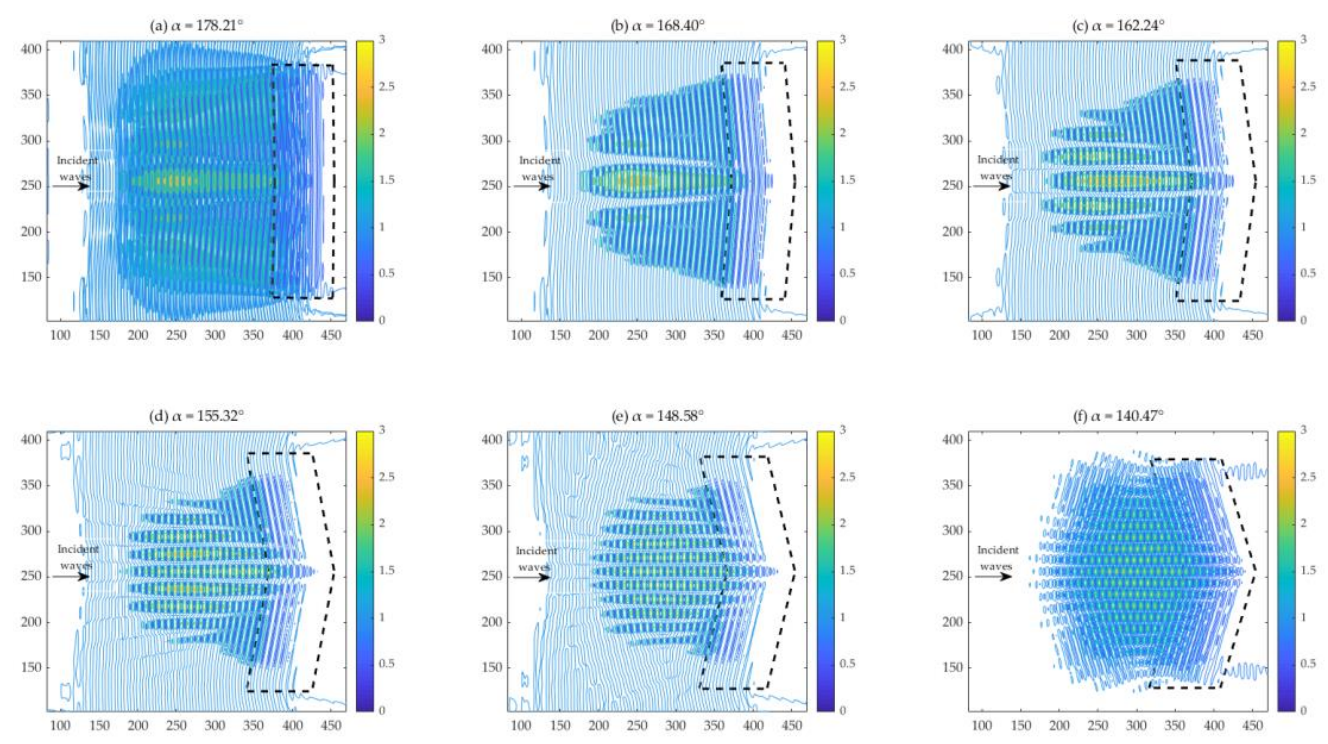

Figure 4. The values of $A_{\max } / A_{0}$ in the scenarios of regular waves under different angles $\alpha$ of $\mathrm{V}$-shaped undulating bottom (The dashed outline refers to the V-shaped undulating bottom range).

Figure 4 shows that no matter what degree $\alpha$ is, there are obvious wave-focusing areas and a series of focal points in front of the V-shaped undulating bottom. According to the principle of coastal protection, the wave amplitudes behind the bottom are possibly weakened owning to enormous waves reflected in front of the bottom. The V-shaped undulating bottom is generally symmetrical about the central axis; the wave-focusing areas are also symmetrical about the central axis. In addition, the wave-focusing areas are generally expand from right to left in front of the bottom in a " $\mathrm{V}$ " shape that is slightly smaller than the " $\mathrm{V}$ " shape of the bottom.

Figure 4 also shows that through the 6 selected representative $\alpha$ angles of the V-shaped undulating bottom, the spatial distributions of the wave amplitudes in the focusing areas owning to Bragg resonance are symmetric about the center of the V-shaped undulating bottom, and the largest wave amplitudes are along the axis of symmetry. By comparison, it is found that the wave-focusing intensity first increases and then weakens with the decreasing V-shaped undulating bottom angles $\alpha=178.21^{\circ}, 168.40^{\circ}, 162.24^{\circ}, 155.32^{\circ}$, $148.58^{\circ}$, and $140.47^{\circ}$. When $\alpha$ is about $162.24^{\circ}$, there are significant focusing areas and focal points, and the focusing intensity at this angle is the strongest. 
4.1.2. Quantitative Analysis of Wave Amplitudes in the Focusing Areas for Regular Waves

To further quantitatively analyze and compare wave amplitude focusing characteristics at different angles $\alpha$, the wave amplitude increases $A_{\max } / A_{0}$ are classified and counted. In addition, under the four levels of $A_{\max } / A_{0}>1, A_{\max } / A_{0} \geq 1.5, A_{\max } / A_{0} \geq 2$, and $A_{\max } / A_{0} \geq 2.5$, the occurrence frequencies of the values of $A_{\max } / A_{0}$ in the whole simulation range are calculated and expressed respectively in the form of $P\left(A_{\max } / A_{0}>1\right)$, $P\left(A_{\max } / A_{0} \geq 1.5\right), P\left(A_{\max } / A_{0} \geq 2\right)$ and $P\left(A_{\max } / A_{0} \geq 2.5\right)$, respectively. The frequency formula of each level is as follows:

$$
P\left(A_{\max } / A_{0} \geq C\right)=\frac{N\left(A_{\max } / A_{0} \geq C\right)}{N_{x} \times N_{y}}
$$

where $C$ is the specified level constant; $N\left(A_{\max } / A_{0} \geq C\right)$ is the number of nodes corresponding to $A_{\max } / A_{0} \geq C ; N_{x}$ and $N_{y}$ are the numbers of nodes on the $x$ and $y$-axis in the whole simulation range respectively. In this section, $C$ is assigned $1,1.5,2$, and 2.5 respectively, $N_{x}=N_{y}=512$.

For example, $\alpha=178.21^{\circ}, 176.42^{\circ}, 174.63^{\circ}, 168.40^{\circ}, 167.52^{\circ}, 162.24^{\circ}, 160.50^{\circ}, 155.32^{\circ}$, $151.93^{\circ}, 148.58^{\circ}$, and $140.47^{\circ}$ are selected for comparison. As there is no wave-focusing effect when $\alpha=90^{\circ}$, it is not analyzed. Figure 5 shows the level-frequency statistical diagrams of wave amplitude changes at different angles $\alpha$.

In Figure $5 \mathrm{a}$, it shows that a series of nodes appear in the simulation range at all selected angles, but $P\left(A_{\max } / A_{0}>1\right)$ and $P\left(A_{\max } / A_{0} \geq 1.5\right)$ gradually decrease with the decrease of angles $\alpha$. $P\left(A_{\max } / A_{0}>1\right)$ decreases from $21.49 \%$ to $15.74 \%$, while $P\left(A_{\max } / A_{0} \geq 1.5\right)$ decreases from $5.32 \%$ to 0 . It can be seen that the focusing area is decreasing. That is because the area of Bragg resonance decreases with the decrease of the angle $\alpha$, and then the wave height focusing areas also reduce. In addition, that is why the range of angles $\alpha$ of V-shaped undulating bottom is $90^{\circ} \leq \alpha \leq 180^{\circ}$.

However, the wave-focusing effects are not only judged by the wave height in the focusing areas but also based on the overall amplitude increases of nodes in the wave height focusing areas, i.e., the values of $A_{\max } / A_{0}$. Therefore, Figure $5 \mathrm{~b}$ further shows the frequency statistic results of $P\left(A_{\max } / A_{0} \geq 2\right)$ and $P\left(A_{\max } / A_{0} \geq 2.5\right)$. It shows that both $P\left(A_{\max } / A_{0} \geq 2\right)$ and $P\left(A_{\max } / A_{0} \geq 2.5\right)$ increase first and then decrease with the decrease of angles $\alpha$. Moreover, when $160^{\circ}<\alpha<168^{\circ}$, the overall value of $P\left(A_{\max } / A_{0} \geq 2\right)$ is larger. That is to say, the total number of nodes of $A_{\max } / A_{0} \geq 2$ is the largest. Meanwhile, when $\alpha=162.24^{\circ}$, the values of $P\left(A_{\max } / A_{0} \geq 2\right)$ and $P\left(A_{\max } / A_{0} \geq 2.5\right)$ are the largest in the simulation range, which implies that the number of nodes corresponding to $A_{\max } / A_{0} \geq 2$ and $A_{\max } / A_{0} \geq 2.5$ is the most, and the wave-focusing effect is the strongest. The spatial distribution of wave amplitude change shows that when $\alpha=162.24^{\circ}$, the scope of wave height focusing areas are relatively concentrated, the wave amplitude increases are the largest as a whole, and the wave-focusing effect is the best.

In conclusion, $\alpha=162.24^{\circ}$ is considered to be the optimal angle for V-shaped undulating bottom. 

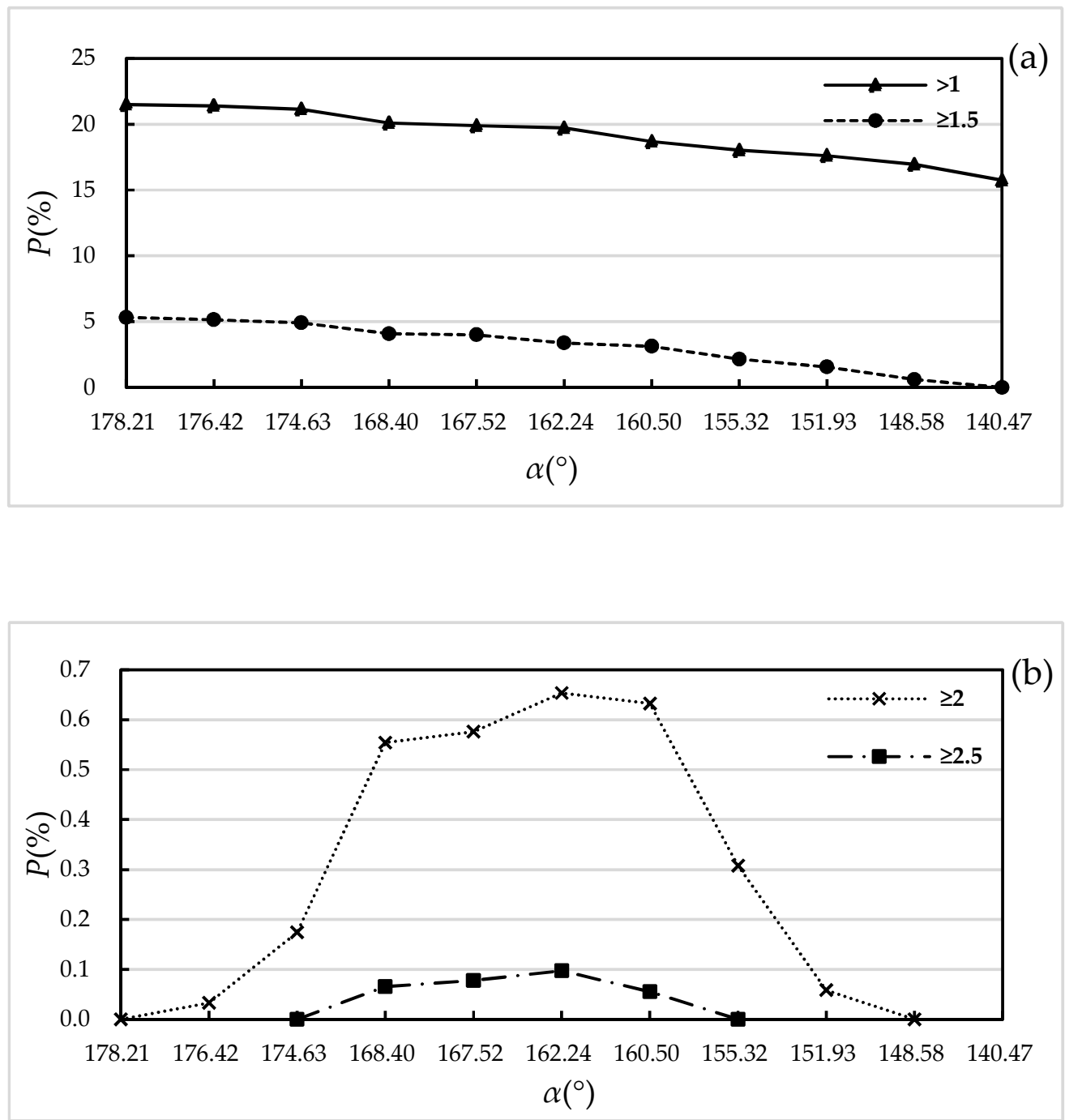

Figure 5. Level-frequency statistical diagrams of wave amplitude changes under different angles $\alpha$ : (a) $A_{\max } / A_{0}>1$ and $A_{\max } / A_{0} \geq 1.5$; (b) $A_{\max } / A_{0} \geq 2$ and $A_{\max } / A_{0} \geq 2.5$.

4.2. Bragg Resonance Focusing Characteristics of Random Waves for V-Shaped Undulating Bottom 4.2.1. The Gaussian Spectrum

The Gaussian spectrum is a symmetric spectrum, and its spectrum pattern is simple and regular. The expression of the Gaussian spectrum requires only 3 parameters, compared with the Jonswap formula, which requires 5 parameters. Therefore, it is more convenient to use the Gaussian spectrum to calculate. In this paper, the two-dimensional Gaussian spectrum pattern is selected, and the expression is shown in Equation (6).

$$
S\left(k_{i}\right)=\frac{\eta^{2}}{\sqrt{2 \pi} \sigma} \exp \left(-\frac{\left(k_{i}-k_{0}\right)^{2}}{2 \sigma^{2}}\right)
$$

where: Gaussian spectrum expression $S\left(k_{i}\right)$, the standard deviation of the height of the wave surface $\eta=\left(\int S(k) d k\right)^{1 / 2}=\sqrt{m_{0}}$, zero-order spectrum moment $m_{0}$, spectral peak wave number $k_{0}$, spectral width parameter $\sigma$, value range of the $i$-th wave number $0 \leq k_{i} / d k \leq N / 4$, the node number in the simulation range $N$. 
The initial wave steepness and spectral width of the random wave are changed by controlling $\eta$ and $\sigma$ respectively. The initial wave steepness $\varepsilon_{0}$, initial amplitude $a_{0}$, and spectral width $B_{0}$ are calculated according to Equations (7)-(9) respectively.

$$
\begin{gathered}
\varepsilon_{0}=2 \eta k_{0} \\
a_{0}=\varepsilon_{0} / k_{0}=2 \eta=2 \sqrt{m_{0}} \\
B_{0}=\sigma / k_{0}
\end{gathered}
$$

The amplitude of the $i$-th wave can be calculated by Equation (10).

$$
a_{i}=\sqrt{2 S\left(k_{i}\right) d k}
$$

The initial wave surface and potential function can be obtained from Equation (11).

$$
\left.\begin{array}{l}
\eta(x, 0)=\sum a_{i} \cos \left(k_{i} x+\theta_{i}\right) \\
\phi^{S}(x, 0)=\sum \frac{g a_{i}}{\omega_{i}} \sin \left(k_{i} x+\theta_{i}\right)
\end{array}\right\}
$$

where: the initial wave surface $\eta(x, 0)$, the initial potential function $\phi^{s}(x, 0)$, the initial phase of the $i$-th wave generated randomly through the program $\theta_{i}$, the gravitational acceleration $g$, the circular frequency of the $i$-th wave $\omega_{i}$, according to the dispersion relation $\omega^{2}=g k \tanh k h$ (water depth $h$ ) in the finite water depth to calculate the $k_{i}$.

Assuming that the initial wave surface and the initial potential function along the $y$-axis are equal, the two-dimension random wave field is extended into a three-dimension random wave field along the $y$-axis.

\subsubsection{Evolution Characteristics of Random Waves on Flat Bottom}

The Gaussian spectrum is used to generate the initial wave field. The initial phases of each simulated wave field are randomly generated. Different initial phases, dispersion relation, and wave modulation instability will cause uneven wave height distributions along the $x$-axis. Therefore, the evolution characteristics of random waves on the flat bottom are first studied in this study. The distributions of significant wave heights $H_{\mathrm{s}}$ along the $x$-axis under three random initial phases in the wave order $M=3$ are shown in Figure 6. It shows that the distributions of significant wave heights along the $x$-axis are greatly different with different initial phases. Here, the node number along the $x$-axis is 512 , and 16 nodes represent one wavelength of incident free surface.

As the number of simulation increases, the significant wave heights $H_{\mathrm{s}}$ under different random initial phases are averaged. The results are shown in Figure 7.

With the increase of the simulation groups, the distributions of significant wave heights $H_{\mathrm{s}}$ along the $x$-axis become more uniform. When the number of simulation groups is more than 10, the significant wave heights are basically stable in the form of a horizontal line, which meets the requirements of analysis. 

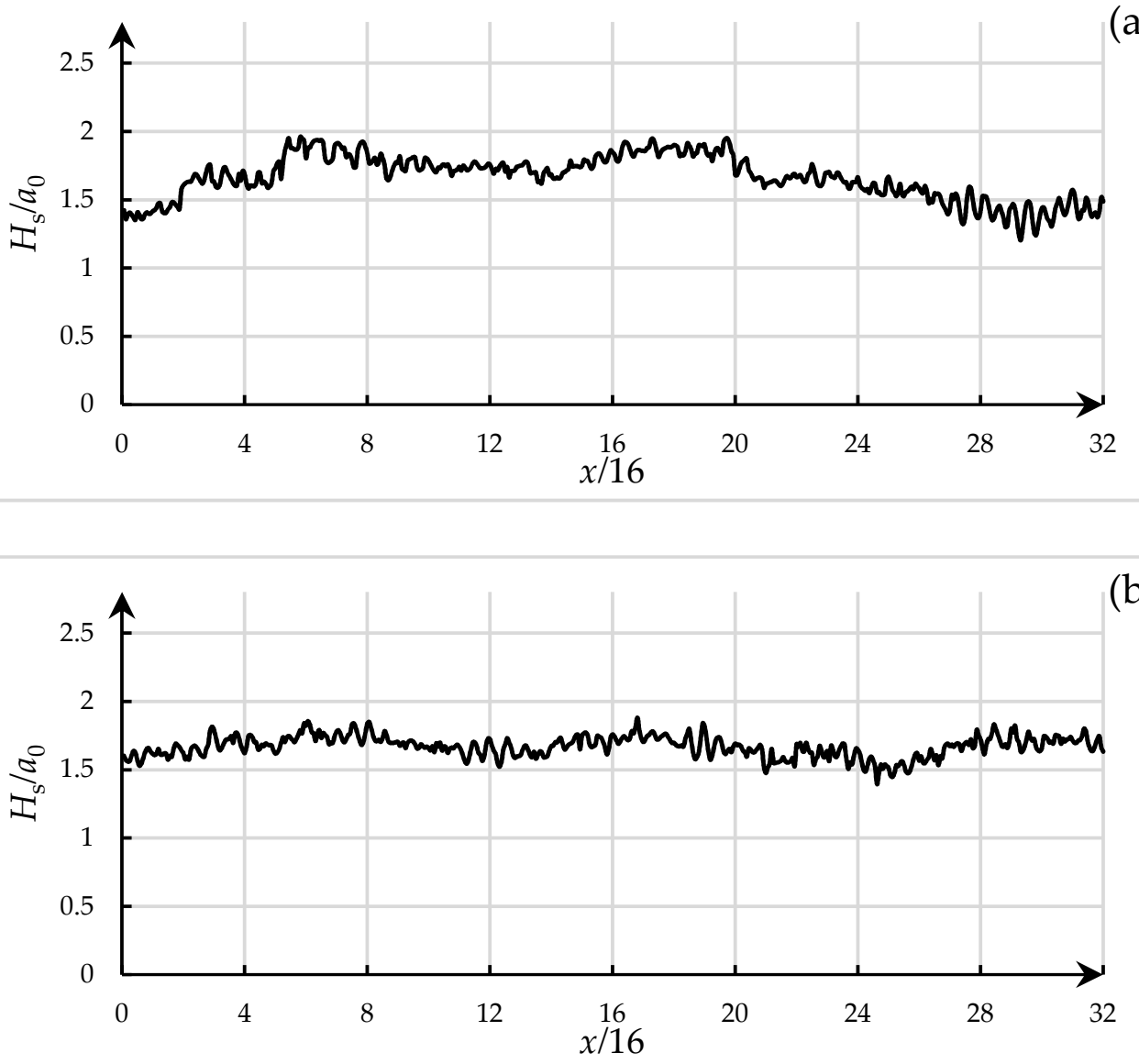

(b)

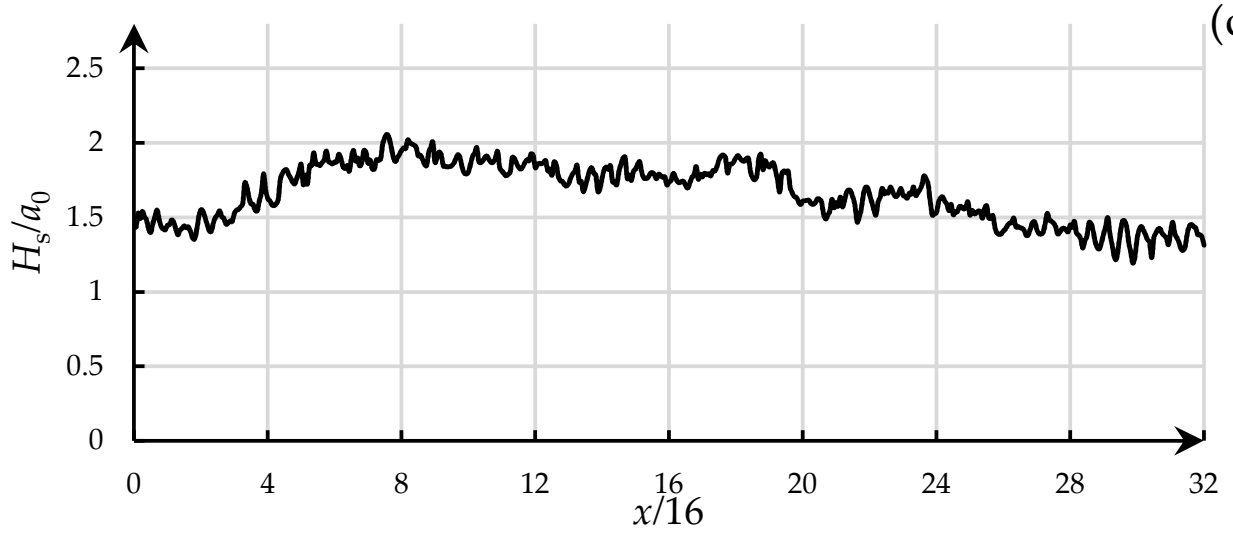

Figure 6. Distributions of significant wave heights $H_{\mathrm{S}}$ along the $x$-axis under three random initial phases for $M=3$ : (a) Initial phase one; (b) Initial phase two; (c) Initial phase three. 


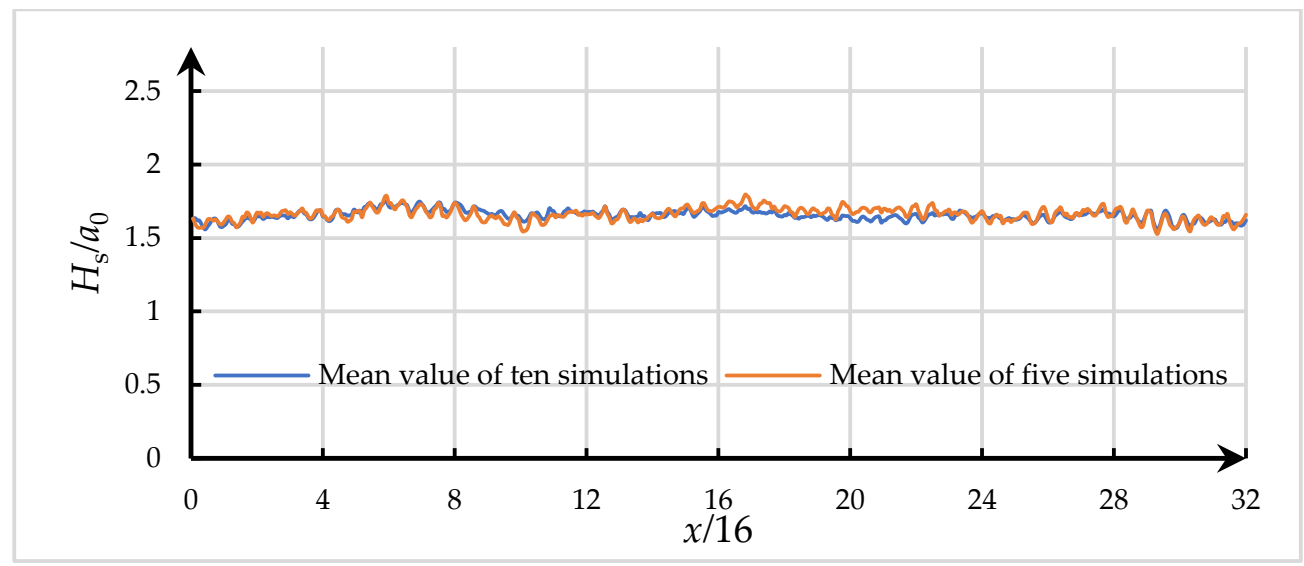

Figure 7. Distributions of average significant wave heights $H_{\mathrm{s}}$ along the $x$-axis under five and ten simulations for $M=3$.

\subsection{Evolution Characteristics of Random Waves on V-Shaped Undulating Bottom}

BFI was proposed by Janssen [56], which is determined by wave steepness and spectrum width. The initial definition is shown in Equation (12), which is converted into the definition of wavenumber spectrum (14) by combining with Equation (13):

$$
\begin{gathered}
B F I=\sqrt{2} \varepsilon_{0} /\left(2 \Delta \omega / \omega_{0}\right) \\
2 \Delta \omega / \omega_{0}=\Delta k / k_{0} \\
B F I=\sqrt{2} \varepsilon_{0} / B_{0}
\end{gathered}
$$

where: the circular frequency $\omega$, the initial circular frequency $\omega_{0}$, the wavenumber of incident random waves $k$, the wavenumber of initial incident random waves $k_{0}$, the spectrum width $B$, the initial spectrum width $B_{0}$, the initial wave steepness $\varepsilon_{0}$.

Janssen proposed that when $B F I$ is greater than or equal to 1.0, satisfying the conditions for generation of modulation instability, the possibility of freak waves is increased. To eliminate the influence of wave modulation instability on the simulation results, the $B F I$ is set at less than 1.0 in this study. Under different combinations of initial wave steepness and

\begin{tabular}{|c|c|c|c|c|c|}
\hline$\varepsilon_{0}$ & $B_{0}$ & $B F I$ & $\varepsilon_{0}$ & $B_{0}$ & $B F I$ \\
\hline \multirow{4}{*}{0.07} & 0.1 & 0.990 & \multirow{4}{*}{0.06} & 0.1 & 0.849 \\
\hline & 0.2 & 0.495 & & 0.2 & 0.424 \\
\hline & 0.3 & 0.330 & & 0.3 & 0.283 \\
\hline & 0.4 & 0.247 & & 0.4 & 0.212 \\
\hline$\varepsilon_{0}$ & $B_{0}$ & $B F I$ & $\varepsilon_{0}$ & $B_{0}$ & $B F I$ \\
\hline \multirow{4}{*}{0.05} & 0.1 & 0.707 & \multirow{4}{*}{0.04} & 0.1 & 0.566 \\
\hline & 0.2 & 0.354 & & 0.2 & 0.283 \\
\hline & 0.3 & 0.236 & & 0.3 & 0.189 \\
\hline & 0.4 & 0.177 & & - & - \\
\hline
\end{tabular}
spectrum width, the values of BFI are listed in Table 4.

Table 4. The values of BFI under the settings of the Gaussian spectrum.

The calculated wave heights $\left(H_{\mathrm{smax}}\right)$ are compared with the incident wave height $\left(H_{\mathrm{s} 0}\right)$. To examine the interactions between random waves and undulating bottom, the spatial distribution characteristics of wave heights due to Bragg resonance are analyzed. Analyzing the combinations of initial wave steepness and initial spectrum width, it is found that there is a good linear relationship between $H_{\mathrm{smax}} / H_{\mathrm{s} 0}$ and $B F I$, as shown in Figure 8. For $B F I$, in the range of $0.15-1.0$, the values of $H_{\mathrm{smax}} / H_{\mathrm{s} 0}$ linearly increase with the increase of $B F I$, so the fitting formula is shown in Equation (15): 


$$
H_{\mathrm{smax}} / H_{\mathrm{s} 0}=0.39 \times B F I+1.09
$$

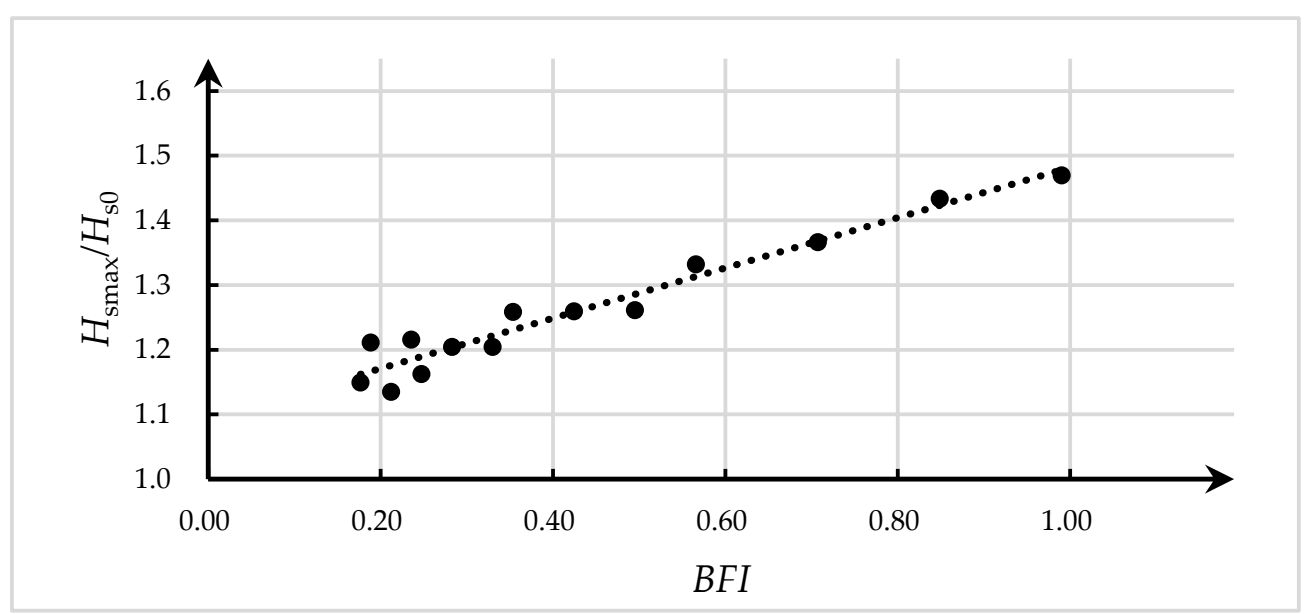

Figure 8. The changing curve of wave height ratio $H_{\mathrm{smax}} / H_{\mathrm{s} 0}$ at the focal points as $B F I$ changes.

The goodness of fit $\left(R^{2}\right)$ in Equation (15) can reach 0.94, indicating that the formula fits well. It is speculated that the calculation results will be more consistent with the line with the increase of the simulation groups. When the value of $B F I$ is more than 0.4 , there is a linear relationship between $H_{\mathrm{smax}} / H_{\mathrm{s} 0}$ and $B F I$; whereas the value of $B F I$ is less than 0.4, $H_{\mathrm{smax}} / H_{\mathrm{s} 0}$ and $B F I$ are weakly linear relation. When the BFI factor is small, in other words, the initial wave steepness of a given spectrum width is small, which indicates that the nonlinear wave interaction is weak. However, a given initial wave steepness has a larger spectrum width, indicating that the frequency bandwidth of wave height distribution is larger. In summary, the smaller the BFI factor is, the smaller $H_{\mathrm{smax}} / H_{\mathrm{s} 0}$ is; BFI and $H_{\mathrm{smax}} / H_{\mathrm{s} 0}$ are becoming more independent, when the incident wave nonlinearity is low.

\section{Conclusions}

In this study, the V-shaped undulating bottom can be regarded as the combination of two parts of oblique bottom undulations relative to the incident waves. The spatial distributions of the wave heights in the focusing areas owning to Bragg resonance of regular wave-bottom interactions are symmetric about the center of the V-shaped undulating bottom, and the largest wave height is distributed along the $x$-axis of symmetry. From these two aspects of spatial distributions and quantitative analysis, it is found that when $\alpha$ is about $162.24^{\circ}$, obvious focusing areas and focal points appear, and the focusing intensity at this angle is the strongest. By optimizing $\alpha$, the wave-focusing effect is improved. When $145^{\circ}<\alpha<180^{\circ}$, the wave amplitude increase at the focal points can reach more than 1.81 times of the initial incident wave amplitude, which is higher than that of the focal points when $\alpha=180^{\circ}$. In particular, when $\alpha=162.24^{\circ}$, the wave-focusing effect is the best and the maximum amplitude increases by 2.87 times of the initial incident wave amplitude. When $\alpha<145^{\circ}$, the maximum amplitude increase of the focal points is less than that of $\alpha=180^{\circ}$. When $\alpha=90^{\circ}$, the maximum amplitude of the focal points is unchanged, i.e., wave energy focusing does not occur.

Therefore, the V-shaped undulating bottom at the angle of $162.24^{\circ}$ is selected to study the random wave-bottom interactions characteristics. It is found that there is a good linear relationship between $H_{\mathrm{smax}} / H_{\mathrm{s} 0}$ and $B F I$, which combines wave steepness and spectrum width. For $B F I$, in the range of $0.15-1.0$, the values of $H_{\mathrm{smax}} / H_{\mathrm{s} 0}$ linearly increase with the increase of $B F I$. 
Author Contributions: Formal analysis, J.S.; investigation, S.X.; methodology: J.T.; software, H.Z., J.T. and J.S.; validation, S.X.; writing—original draft preparation, H.Z.; writing-review and editing, A.T. All authors have read and agreed to the published version of the manuscript.

Funding: This research is supported financially by the National Key Research and Development Program of China (2020YFD0900701) and the National Natural Science Foundation of China (U1706230).

Institutional Review Board Statement: Not applicable.

Informed Consent Statement: Not applicable.

Data Availability Statement: Not applicable.

Conflicts of Interest: The authors declare no conflict of interest.

\section{References}

1. Ahamed, R.; McKee, K.; Howard, I. Advancements of wave energy converters based on power take off (PTO) systems: A review. Ocean Eng. 2020, 204, 107248. [CrossRef]

2. Hayward, J.; Behrens, S.; McGarry, S.; Osman, P. Economic modelling of the potential of wave energy. Renew. Energy 2012, 48, 238-250. [CrossRef]

3. Mustapa, M.A.; Yaakob, O.; Ahmed, Y.M.; Rheem, C.K.; Koh, K.; Adnan, F.A. Wave energy device and breakwater integration: A review. Renew. Sustain. Energy Rev. 2017, 77, 43-58. [CrossRef]

4. Rahm, M.; Svensson, O.; Boström, C.; Waters, R.; Leijon, M. Experimental results from the operation of aggregated wave energy converters. IET Renew. Power Gener. 2012, 6, 149-160. [CrossRef]

5. Bragg, W.H. X-rays and crystalline structure. Science 1914, 40, 795-802. [CrossRef] [PubMed]

6. Davies, A.G. The reflection of wave energy by undulations on the seabed. Dyn. Atmos. Ocean. 1982, 6, 207-232. [CrossRef]

7. Heathershaw, A.D. Seabed-wave resonance and sand bar growth. Nature 1982, 296, 343-345. [CrossRef]

8. Davies, A.G.; Heathershaw, A.D. Surface-wave propagation over sinusoidally varying topography. J. Fluid Mech. 1984, 144, 419-443. [CrossRef]

9. Mitra, A.; Greenberg, M.D. Slow interactions of gravity waves and a corrugated seabed. Trans. ASME J. Appl. Mech. 1984, 51, 251-255. [CrossRef]

10. Mei, C.C. Resonant reflection of surface water waves by periodic sandbars. J. Fluid Mech. 1985, 152, 315-335. [CrossRef]

11. Kirby, J.T. A general wave equation for waves over rippled beds. J. Fluid Mech. 1986, 162, 171-186. [CrossRef]

12. Bailard, J.A.; Devries, J.W.; Kirby, J.T. Considerations in using Bragg reflection for storm erosion protection. J. Waterw. Port Coast. Ocean Eng. 1992, 118, 62-74. [CrossRef]

13. Bailard, J.A.; Devries, J.; Kirby, J.T.; Guza, R.T. Bragg reflection breakwater: A new shore protection method? In Proceedings of the 22nd International Conference on Coastal Engineering Proceedings, Delft, The Netherlands, 2-6 July 1990; pp. $1702-1715$.

14. Kirby, J.T.; Anton, J.P. Bragg reflection of waves by artificial bars. In Proceedings of the 22nd International Conference on Coastal Engineering Proceedings, Delft, The Netherlands, 2-6 July 1990; pp. 757-768.

15. O'Hare, T.J.; Davies, A.G. Sand bar evolution beneath partially-standing waves: Laboratory experiments and model simulations. Cont. Shelf Res. 1993, 13, 1149-1181. [CrossRef]

16. Yu, J.; Mei, C.C. Do longshore bars shelter the shore? J. Fluid Mech. 2020, 404, 251-268. [CrossRef]

17. Howard, L.N.; Yu, J. Normal modes of a rectangular tank with corrugated bottom. J. Fluid Mech. 2007, 593, 209-234. [CrossRef]

18. Weidman, P.D.; Herczyński, A.; Yu, J.; Howard, L.N. Experiments on standing waves in a rectangular tank with a corrugated bed. J. Fluid Mech. 2015, 777, 122-150. [CrossRef]

19. Mei, C.C.; Hara, T.; Naciri, M. Note on Bragg scattering of water waves by parallel bars on the seabed. J. Fluid Mech. 1988, 186, 147-162. [CrossRef]

20. Liu, Y.; Yue, D.K.P. On generalized Bragg scattering of surface waves by bottom ripples. J. Fluid Mech. 1998, 356, 297-326. [CrossRef]

21. Alam, M.R.; Liu, Y.; Yue, D.K.P. Oblique sub- and super-harmonic Bragg resonance of surface waves by bottom ripples. J. Fluid Mech. 2010, 643, 437-447. [CrossRef]

22. Couston, L.A.; Jalali, M.A.; Alam, M.R. Shore protection by oblique seabed bars. J. Fluid Mech. 2017, 815, 481-510. [CrossRef]

23. Alam, M.R.; Liu, Y.; Yue, D.K.P. Attenuation of short surface waves by the sea floor via nonlinear sub-harmonic interaction. J. Fluid Mech. 2011, 689, 529-540. [CrossRef]

24. Zhang, J.; Benoit, M. Effect of finite amplitude of bottom corrugations on Fabry-Perot resonance of water waves. Phys. Rev. E 2019, 99, 053109. [CrossRef] [PubMed]

25. Porter, D.; Staziker, D.J. Extensions of the mild-slope equation. J. Fluid Mech. 1995, 300, 367-382. [CrossRef]

26. Athanassoulis, G.; Belibassakis, K.A. A consistent coupled-mode theory for the propagation of small-amplitude water waves over variable bathymetry regions. J. Fluid Mech. 1999, 389, 275-301. [CrossRef]

27. Belibassakis, K.; Athanassoulis, G.; Gerostathis, T. A coupled-mode model for the refraction-diffraction of linear waves over steep three-dimensional bathymetry. Appl. Ocean Res. 2001, 23, 319-336. [CrossRef] 
28. O'Hare, T.J.; Davies, A.G. A new model for surface wave propagation over undulating topography. Coast. Eng. 1992, 18, 251-266. [CrossRef]

29. Seo, S.N. Transfer matrix of linear water wave scattering over a stepwise bottom. Coast. Eng. 2014, 88, 33-42. [CrossRef]

30. Madsen, P.A.; Fuhrman, D.R.; Wang, B. A Boussinesq-type method for fully nonlinear waves interacting with a rapidly varying bathymetry. Coast. Eng. 2006, 53, 487-504. [CrossRef]

31. Dommermuth, D.G.; Yue, D.K.P. A high-order spectral method for the study of nonlinear gravity waves. J. Fluid Mech. 1987, 184, 267-288. [CrossRef]

32. Guazzelli, E.; Rey, V.; Belzons, M. Higher-order Bragg reflection of gravity surface waves by periodic beds. J. Fluid Mech. 1992, 245, 301-317. [CrossRef]

33. Chang, H.K.; Liou, J.C. Long wave reflection from submerged trapezoidal breakwaters. Ocean Eng. 2007, 34, 185-191. [CrossRef]

34. Wen, C.C.; Tsai, L.H. Numerical simulation of Bragg reflection based on linear waves propagation over a series of rectangular seabed. China Ocean Eng. 2008, 22, 71-86.

35. Zhang, J.S.; Jeng, D.S.; Liu, P.F.; Zhang, C.; Zhang, Y. Response of a porous seabed to water waves over permeable submerged breakwaters with Bragg reflection. Ocean Eng. 2012, 43, 1-12. [CrossRef]

36. Ouyang, H.T.; Chen, K.H.; Tsai, C.M. Wave characteristics of Bragg reflections from a train of submerged bottom breakwaters. J. Hydro-Environ. Res. 2016, 11, 91-100. [CrossRef]

37. Yueh, C.Y.; Chuang, S.H.; Wen, C.C. Bragg reflection of water waves due to submerged wavy plate breakwater. J. Hydro-Environ. Res. 2018, 21, 52-59. [CrossRef]

38. Ning, D.; Chen, L.; Zhao, M.; Teng, B. Experimental and numerical investigation of the hydrodynamic characteristics of submerged breakwaters in waves. J. Coast. Res. 2016, 32, 800-813. [CrossRef]

39. Shih, R.S.; Weng, W.K. Experimental determination of the performance characteristics of an undulating submerged obstacle. Ships Offshore Struct. 2016, 11, 129-141. [CrossRef]

40. Liu, Y.; Li, H.-J.; Zhu, L. Bragg reflection of water waves by multiple submerged semi-circular breakwaters. Appl. Ocean Res. 2016, 56, 67-78. [CrossRef]

41. Zheng, J.; Yao, Y.; Chen, S.; Chen, S.; Zhang, Q. Laboratory study on wave-induced setup and wave-driven current in a 2DH reef-lagoon-channel system. Coast. Eng. 2020, 162, 103772. [CrossRef]

42. Elandt, R.B.; Couston, L.A.; Lambert, R.A.; Alam, M.R. Bragg Resonance of Gravity Waves and Ocean Renewable Energy. Integr. Syst. Innov. Appl. 2015, 211-226. [CrossRef]

43. Tao, A.F.; Yan, J.; Wang, Y.; Zheng, J.H.; Fan, J.; Qin, C. Wave power focusing due to the Bragg resonance. China Ocean Eng. 2017, 31, 458-465. [CrossRef]

44. Zhang, C.; Ning, D. Hydrodynamic study of a novel breakwater with parabolic openings for wave energy harvest. Ocean Eng. 2019, 182, 540-551. [CrossRef]

45. Phillips, O.M. On the dynamics of unsteady gravity waves of finite amplitude. I: The elementary interactions. J. Fluid Mech. 1960, 9, 193-217. [CrossRef]

46. Wu, G.Y. Direct Simulation and Deterministic Prediction of Large Scale Nonlinear Ocean Wave Field. Ph.D. Thesis, Massachusetts Institute of Technology, Cambridge, MA, USA, 2004.

47. Zhao, X.Z.; Sun, Z.C.; Liang, S.X. Efficient focusing models for generation of freak waves. China Ocean Eng. 2009, $23,429-440$.

48. Tao, A.-F.; Zheng, J.-H.; Mee, M.S.; Chen, B.-T. Re-study on recurrence period of Stokes wave train with High Order Spectral method. China Ocean Eng. 2011, 25, 679-686. [CrossRef]

49. Seiffert, B.R.; Ducrozet, G.; Bonnefoy, F. Simulation of breaking waves using the high-order spectral method with laboratory experiments: Wave-breaking onset. Ocean Model. 2017, 119, 94-104. [CrossRef]

50. Seiffert, B.R.; Ducrozet, G. Simulation of breaking waves using the high-order spectral method with laboratory experiments: Wave-breaking energy dissipation. Ocean Dyn. 2018, 68, 65-89. [CrossRef]

51. Song, J.; Zhuang, Y.; Wan, D. New wave spectrums models developed based on HOS method. In Proceedings of the 28th International Ocean and Polar Engineering Conference, Sapporo, Japan, 10-15 June 2018; pp. 524-531.

52. Guo, Q.; Alam, M.R. Prediction of oceanic rogue waves through tracking energy fluxes. In Proceedings of the 36th International Conference on Ocean, Offshore and Arctic Engineering, Trondheim, Norway, 25-30 June 2017.

53. Gouin, M.; Ducrozet, G.; Ferrant, P. Propagation of 3D nonlinear waves over an elliptical mound with a High-Order Spectral. Eur. J. Mech. B/Fluids 2017, 63, 9-24. [CrossRef]

54. Fan, J.; Zheng, J.; Tao, A.; Liu, Y. Upstream-propagating waves induced by steady current over a rippled bottom: Theory and experimental observation. J. Fluid Mech. 2021, 910, A49. [CrossRef]

55. Zakharov, V. Stability of periodic waves of finite amplitude on the surface of a deep fluid. J. Appl. Mech. Tech. Phys. 1968, 9, 86-94. [CrossRef]

56. Janssen, P. Nonlinear four-wave interactions and freak waves. J. Phys. Oceanogr. 2003, 33, 863-884. [CrossRef] 